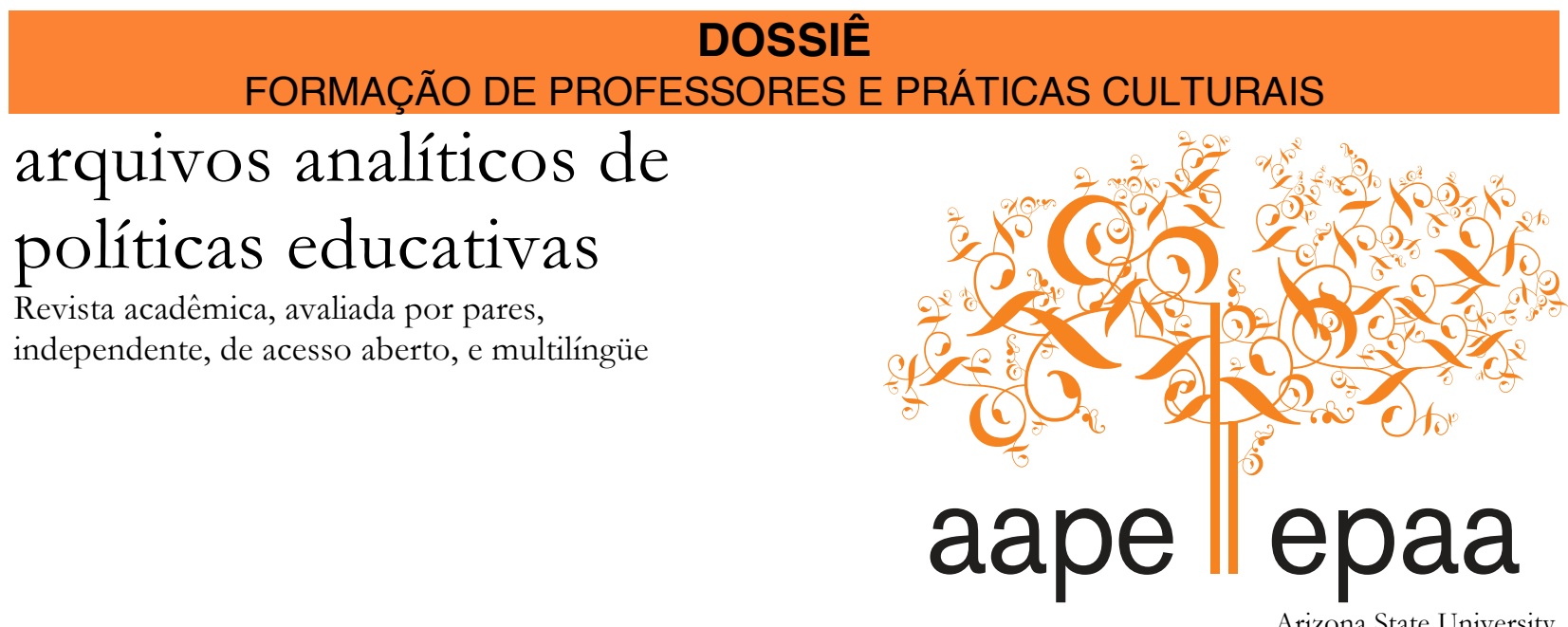

Arizona State University

Volume 21 Número $23 \quad 25$ de março, 2013

ISSN 1068-2341

\title{
Espaço de Formação Docente: aulas de História da Educação
}

\author{
Dóris Bittencourt Almeida \\ Universidade Federal do Rio Grande do Sul \\ Brasil
}

Citação: Almeida, D.B. (2013) Espaço de Formação Docente: aulas de História da Educação. Arquivos Analíticos de Políticas Educativas, 21(23). Dossiê Formação de Professores e Práticas Culturais: descobertas, enlaces, experimentações. Editoras convidadas: Carla Beatriz Meinerz, Dóris Maria Luzzardi Fiss \& Sônia Mara Moreira Ogiba. Recuperado [data] http://epaa.asu.edu/ojs/article/view/1154

Resumo: O texto discute os significados da História da Educação como disciplina curricular especialmente presente nos Cursos de Pedagogia, considerando sua relevância no processo de formação docente. A História da Educação, em sua dupla identidade, disciplina e campo de pesquisa, situa-se em uma zona de fronteira, aproximando-se ora da História, ora da Educação. O estreitamento desses diálogos apoia-se na História Cultural, como tendência historiográfica contemporânea que contribui para a renovação da historiografia ocidental. Ao longo do artigo, argumenta-se a importância de se pensar em aulas de História da Educação que encantem as alunas, que procurem valorizar seus saberes, anseios e ancestralidades, portanto, estejam atreladas às vivências e realidades educacionais do país na contemporaneidade. Nesse sentido, as aulas devem procurar responder a indagações que partam do contexto em que se vive a fim de que cada aluna possa refletir e conseguir atribuir sentidos efetivos e afetivos a essa disciplina. Palavras-chave: Formação Docente; História da Educação; História e Educação; História Cultural.

\section{Space of Faculty Formation: History of Education classes}

Página web: http:/ / epaa.asu.edu/ojs/

Artigo recebido: 29/06/2012

Facebook: /EPAAA

Twitter: @epaa_aape 


\begin{abstract}
The text discusses the meaning of history of education as a curricular subject present especially in pedagogy courses, taking in consideration its relevance in the process of faculty formation. The History of Education, in its double identity, subject and researching area, is located in a border zone, at times approaching History, at times Education. The narrowing of these dialogues relies on Cultural History, as contemporary historiographical trend that contributes to the renewal of Western historiography. Throughout the article argues the importance of thinking about History of Education classes that delight students, seeking to value their knowledge, yearnings and ancestries, therefore, being linked to the educational experiences and realities of the country in its contemporaneity. In this sense, the classes should seek to answer questions that depart from the context in which we live so that each student can reflect and achieve effective and affective meanings attributed to this discipline.
\end{abstract}

Keywords: Faculty Formation; History of Education; History and Education; Cultural History.

\title{
Área de Formación Docente: clases de Historia de la Educación
}

Resumen: Este artículo discute los significados de la Historia de la Educación como asignatura curricular especialmente en los Cursos de Pedagogía, teniendo en cuenta su importancia en el proceso de formación docente. La Historia de la Educación en su doble identidad, disciplina y campo de investigación, se encuentra en una zona fronteriza, acercándose a veces de la Historia, y a veces de la Educación. El estrechamiento de estos diálogos se apoya en la Historia Cultural, como tendencia historiográfica contemporánea que contribuye para la renovación de la historiografía occidental. A lo largo del artículo se argumenta la importancia de pensar en clases de Historia de la Educación que encanten a las alumnas, que busquen valorar sus saberes, preocupaciones y ancentralidades, por lo tanto, que estén vinculadas a las vivencias y realidades educativas del país en la contemporaneidad. En este sentido, las clases deben tratar de responder a las preguntas que partan del contexto en el que vivimos para que cada alumna pueda reflexionar y lograr atribuir sentidos efectivos y afectivos a esta disciplina.

Palabras clave: Formación Docente; Historia de la Educación; Historia y Educación; Historia Cultural.

\section{História e Educação}

E a história humana não se desenrola apenas nos campos de batalha e nos gabinetes presidenciais. Ela se desenrola também nos quintais, entre plantas e galinhas, nas ruas dos subúrbios, nas casas de jogos, nos prostíbulos, nos colégios, nas usinas, nos namoros de esquinas. Disso eu quis fazer a minha poesia. Dessa matéria humilde e humilhada, dessa vida obscura e injustiçada, porque o canto não pode ser uma traição à vida, e só é justo cantar se o nosso canto arrasta consigo as pessoas e as coisas que não têm voz.

(Ferreira Gullar, 1999)

Os escritos de Ferreira Gullar inspiram a tessitura deste texto e, de certa forma, traduzem meus sentimentos quando avalio os significados da História da Educação no processo de formação de futuras professoras. Portanto, escrever acerca deste tema é algo que seduz e inquieta.

"É-se sempre um pouco nativo dos contextos que se estuda" (Sarmento, 2003, p. 159), nossas escolhas intelectuais são permeadas por subjetividades e pertencimentos. Ao escolher por um campo de estudos, nos revelamos um pouco e este envolvimento não implica em ausência de rigor formal 
ou em afastamento de vigilância epistemológica (Bourdieu, Chamboredon e Passeron, 1999), próprios de toda atividade científica. Ao contrário, permite que a criatividade seja potencializada, justamente, pelo fato de se estar engajado com aquilo que se está investigando. Para Ribeiro (1999, p. 191), "nada é apenas objeto, porque, sempre, de alguma forma, tem a ver intimamente com o sujeito que o está estudando."

Permito-me evocar minhas memórias para narrar um pouco daquilo que vivi como professora e pesquisadora. Percorro as trilhas da educação há muito tempo. Fiz duas escolhas importantes que me acompanham cotidianamente: a Educação e a História. De certa forma, elas se fundem e se complementam no trabalho docente que desenvolvo e nas pesquisas relacionadas à História da Educação, permitindo que eu consolide a opção intelectual que me situa em uma espécie de zona de fronteira.

As incursões por esses dois territórios, a Educação e a História, possibilitam aventuras por novos caminhos, amadurecimento de algumas posições, revisão de tantas outras e percepção das inter-relações entre elas. Os possíveis riscos de escolher por esta área de fronteira são compensados pelo crescimento intelectual proporcionado pelos estudos nos domínios da Educação e da História. Segundo Boaventura de Sousa Santos (1993), "a leveza da zona fronteiriça torna-a muito sensível aos ventos. É uma porta de vai-e-vem e, como tal, nunca está escancarada, nem nunca está fechada" (p. 50).

Se História e História da Educação estão muito próximas uma da outra, se é difícil estabelecer seus limites, é importante estreitar esses diálogos e isso implica em uma discussão acerca da História Cultural, como tendência historiográfica contemporânea que contribui para a renovação da historiografia ocidental. A escrita da história, de certa forma, passa a rejeitar a história política factual, renunciando as certezas e racionalidades que davam o tom da historiografia dos séculos XIX e parte do século XX. A História da Educação caracteriza-se por uma espécie de hibridismo, está em uma situação borderline, e, portanto, faz contatos ora com a Educação, ora com a História, e é nesse sentido que se notam aproximações cada vez mais fecundas entre História da Educação e História Cultural. Talvez se possa dizer que aqui se acabam as fronteiras (Fonseca, 2008), pois a primeira vale-se dos procedimentos metodológicos, conceitos e referenciais teóricos da segunda. É na riqueza dessas interfaces que se busca compreender os processos educativos e escolares de diferentes culturas ao longo do tempo.

Em relação ao estatuto da História da Educação, importa dizer que, por um lado, é disciplina, como área de conhecimento que fundamenta a formação docente, importante a todos aqueles que desejam seguir a profissão docente. Por outro, também se constitui em campo de pesquisas que agrega historiadores, pedagogos entre outros pesquisadores. Longe de pensar em fragmentação, essa dupla identidade da História da Educação a potencializa e "amplia nosso universo como sujeitos históricos” (Bastos e Stephanou, 2004, p. 427). Entretanto, nesses escritos, procuro priorizar uma reflexão acerca da História da Educação enquanto disciplina ${ }^{1}$ curricular, especialmente presente nos Cursos de Pedagogia, considerando sua relevância no processo de formação docente.

\section{De que lugar se está falando?}

É importante entender que concepções teóricas se fazem presentes nas aulas de História da Educação e perceber como esses referenciais se traduzem na escolha dos temas e nas abordagens promovidas pela disciplina. Para tanto, ainda que brevemente, comento alguns aspectos que

\footnotetext{
${ }^{1}$ Ao referir-me ao caráter disciplinar da História da Educação, trato de seu lugar como área de conhecimento. Isso se afasta de pensar na História da Educação dentro de um paradigma disciplinar, como conhecimento disciplinado, de acordo com o entendimento da ciência moderna, conforme explica Boaventura de Sousa Santos (2002).
} 
marcam a produção historiográfica, em diferentes épocas, e suas relações com a História da Educação.

Ao longo do século XIX, a História, de modo geral, era entendida essencialmente como uma narrativa de fatos passados. Postulava-se o estudo da individualidade irreproduzível e única dos atos humanos, com destaque para figuras das elites e suas biografias. Era uma história de viés totalizante, calcada na homogeneidade, sem espaço para qualquer diferença, que expressava uma visão masculina, europeia, branca, adulta e heterossexual. Mulheres, outros grupos étnicos, jovens, crianças, minorias sexuais, entre tantos outros sujeitos, foram excluídos das tramas da História. Para Bittencourt (2008), nessa forma de escrever a história, conhecida por Historicismo ou, comumente, História tradicional, "cada fato histórico é único e sem possibilidade de repetição, devendo a reconstrução de um passado ter como base a objetividade para ser "história verdadeira" (p. 141). Assim, o Historicismo reconhece que o passado pode ser reconstituído, cabendo ao historiador desvelá-lo, através do recolhimento de fontes consideradas válidas, ordenar cronologicamente e narrar os fatos mais relevantes, mantendo uma postura de objetividade e neutralidade. Essas fontes validadas pelo Historicismo limitam-se aos documentos escritos de caráter oficial, entendidos como provas do que realmente teria ocorrido. O motor das transformações históricas, nessa concepção historiográfica, é o Estado e as ações dos governantes políticos. São concepções da História a partir de perspectivas lineares, não problematizadoras, preocupadas com a mera apresentação de fatos eminentemente políticos, como representações realistas e objetivas do passado, em detrimento de outras esferas da vida social.

Nos primeiros trinta anos do século XX, a produção historiográfica iniciou uma renovação, com o objetivo de ultrapassar o Historicismo. Na busca de uma compreensão mais fecunda da sociedade, o conhecimento histórico começou a se revelar cada vez mais pluridisciplinar, ampliaram-se os conceitos e temáticas partilhadas, bem como o diálogo com outras áreas do conhecimento. A História encontrou aliados em outros campos, como Economia, Literatura, Artes, Linguagem, Antropologia.

Bertold Brecht, em seu clássico "Perguntas de um trabalhador que lê", em 1936, questionou, talvez antes de muitos historiadores, por que a História se omitia de contar as trajetórias daqueles e daquelas que tornaram possíveis as realizações dos personagens que apareciam nos livros. No poema, expressa o desconforto de um operário que não se sente incluído na História, pois no livro, que tem em suas mãos, "só aparecem os nomes dos reis". Indaga: "Cada página, uma vitória. Quem cozinhava o banquete? A cada dez anos, um grande homem. Quem pagava a conta? Tantas histórias, tantas questões"”.

Assim iniciou-se o declínio da história apenas focada na esfera política. Com a publicação, em 1929, do primeiro número da Revista dos Annales, sob a direção de Marc Bloch e Lucien Febvre, ampliou-se o domínio historiográfico, a busca pela totalidade social, pela redefinição de conceitos fundamentais como documento, fato histórico, tempo e sujeito histórico. As novas tendências passaram a insistir na longa duração e centraram a atenção na atividade econômica, na organização social, na psicologia coletiva, enfim, na aproximação da História com outras ciências. Um dos pressupostos da Escola dos Annales era no sentido de constituir uma história-problema para fornecer respostas às demandas do presente. Ela fazia críticas à história política como motor da história, falava da história das mentalidades coletivas, valorizava temáticas econômicas e, diante disso, multiplicavam-se os temas ligados à micro-história.

Essas novas concepções de História, de certa forma, romperam com os paradigmas instituídos na Modernidade, que privilegiavam as grandes narrativas como ícones do passado. As

\footnotetext{
${ }^{2}$ Brecht, B. Perguntas de um trabalhador que lê. Disponível em: http:/ / recantodasletras.uol.com.br. Acesso em:
} 28 abr. 2012. 
abordagens tradicionais da História, com as quais fomos acostumados a conviver, concentravam-se nos feitos dos chamados grandes homens (Burke, 1996) e acabavam por negligenciar o papel da maioria dos indivíduos anônimos enquanto fazedores da História de seu tempo. Além disso, sustentavam-se essencialmente na documentação escrita, pois nela acreditava-se estar guardada toda a verdade do passado. Para Rago, "o passado estava lá, bem distinto do presente como coisa, um baú talvez, guardado num arquivo fixo, organizado, estável, à espera de ser 'desvelado', 'recuperado', tirado do esquecimento, libertado em sua pureza" (2003, p. 32). A História era pensada como algo asséptico, limitada a narrar o passado e nunca duvidar dele, acreditando que este passado poderia ser descoberto em sua totalidade. Thomson $(1997 ; 2001 ; 2002)$ diz que os historiadores têm outro dever para com a sociedade e a história: a responsabilidade de contestar mitos históricos que privilegiam certas pessoas em detrimento de outras.

Esse afastamento dos paradigmas do passado não é tarefa simples, tampouco imediata. É preciso meditar e estudar muito para desapegar-se, ao menos, de algumas dessas âncoras com as quais estamos acostumados a entender o mundo e, desse modo, perceber que vivemos uma época marcada pela relatividade dos saberes, pela ausência de certezas, pela fragmentação dos sujeitos, pela heterogeneidade, entre tantos outros conceitos. Neste sentido, Boaventura de Sousa Santos afirma:

Vivemos num tempo atônito que ao debruçar-se sobre si próprio descobre que seus pés são um cruzamento de sombras, sombras que vêm do passado que ora pensamos já não sermos, ora pensamos não termos ainda deixado de ser, sombras que vêm do futuro que ora pensamos já sermos, ora pensamos vir a ser (2002, p. 5).

Estamos neste cruzamento de sombras: questiona-se aquilo que parece seguro, procura-se um afastamento da verdade cartesiana, essencialista. Buscam-se novos paradigmas que se aproximem de referências mais plurais, menos assentadas em certezas imutáveis, mas pautadas pela perspectiva da descontinuidade. Neste sentido, elege-se a construção, e não apenas a mera revelação, confirmação ou descoberta da essência dos fatos. Percebe-se a subjetividade que envolve o estudo da História da Educação, e isso se afasta do imediatismo de esperar encontrar a resposta certa no passado. Importa aceitar a incompletude, a falta de inteireza do conhecimento (Sarmento, 2003), aceitar a impossibilidade de alcançá-lo em sua plenitude, entender que o estudo do passado não é mera transposição da realidade acontecida, mas que sobre ela foram feitos recortes, exclusões, seleções. Vivemos uma época marcada pela pluralidade, pela diversidade, em que o que era visto como absoluto parece não encontrar mais espaço de sustentabilidade. Como assinala Roger Chartier: [...] o tempo das dúvidas e dos questionamentos é também um tempo de dispersão: todas as tradições historiográficas perderam sua unidade, todas se fragmentaram entre perspectivas diversas, às vezes contraditórias, que multiplicaram os objetos de investigação, os métodos, as 'histórias' (2001, p. 116).

Chartier aponta para um "abandono dos paradigmas dominantes" (2002, p. 61), fala em "tempo de incerteza, crise epistemológica, reviravolta crítica" (p. 81), buscando definir as novas tendências do conhecimento científico. Michel Foucault, em seus estudos (1992, 1995, 2001a, 2001b), também propõe um afastamento da história de cunho tradicional, revolucionando antigas certezas, o autor rejeita a História calcada na essência dos fatos. Defende uma história problematizadora, não preocupada com a busca da totalidade, mas, sim, com o recorte e com as descontinuidades. Aproxima-se da Antropologia, preocupa-se em desconstruir o real, não mais para revelá-lo em sua essência. Foucault rompe com a noção consolidada de sujeito moderno, afirmando que este não é dotado de uma consciência e de autonomia, mas é regulado e produzido pelos discursos de uma época e pelos poderes que visam discipliná-lo. As histórias narradas perderam muito de seu sentido original glorioso e heroico, sua energia explicativa inicial, dos grandes feitos modernizadores, cedeu lugar à consciência de viver numa época multicultural e de interesses pluri-orientados. 
A área de História da Educação, em seus diálogos com a História, também passa por uma revolução, tanto em seus contornos teórico-metodológicos quanto no alargamento de seus objetos e de suas fontes. Hoje, o ensino e a pesquisa neste campo de conhecimento são muito mais imaginativos e inovadores do que no passado recente. Observa-se um respeitável avanço nas pesquisas, com a presença de novos atores educativos e desenvolvimento de investigações que penetram o interior das escolas e seus processos educativos particulares. Chartier (2001) alerta para a necessidade de se estudar objetos culturais em sua materialidade. Então, a cultura escolar, o cotidiano e o funcionamento de escolas, os agentes educacionais, a imprensa pedagógica, livros didáticos, tendências de estudos mais localizados, realidades mais circunscritas em um espaço pequeno de tempo constituem-se em temas discutidos nas aulas dessa disciplina.

Ainda segundo Chartier, "no lugar ocupado pelos personagens e pelos heróis das antigas narrativas, a 'nova história' instala entidades anônimas e abstratas; ao tempo espontâneo da consciência, ela substituía uma temporalidade construída, hierarquizada, articulada" (2001, p. 45). Valorizaram-se os esquecidos, instituindo o desejo de restaurar o papel dos indivíduos nas tramas da História. Nesse sentido, passam a ocupar espaço novos atores sociais, práticas e sentidos da História. Os sujeitos, até então excluídos/esquecidos pela História da Educação, não foram vidas de silêncio, mas, sim, vidas relegadas ao silêncio, que não encontraram uma escuta sensível e que passaram despercebidas pelo tempo. A História, agora, busca construir uma trama, tendo como personagens aqueles e aquelas "sobre cujo silêncio foi construída a história" (Rancière, 1995, p. 54).

Michel de Certeau relativiza e problematiza o conceito de marginalidade que, para ele, assume outros significados. Do ponto de vista semântico, a palavra nos induz a pensar naquilo que está de fora e que, portanto, ocupa um espaço menor que o todo. Certeau relativiza essa compreensão ao explicar o conceito de "marginalidade de massa" (1996, p. 44), e isso afasta a possibilidade de pensar que o marginal se refere a pequenos grupos, ao contrário, identifica-se mais com a ideia da marginalidade enquanto uma "maioria silenciosa" (p. 44).

Então, coerente com as mudanças historiográficas que ocorreram ao longo do tempo, argumenta-se que a disciplina História da Educaşão deve ir muito além da perspectiva de apenas apresentar biografias de notáveis educadores, comumente eleitos os europeus como os merecedores de terem suas concepções educacionais estudadas, ou constatar os fundamentos pedagógicos em uma sequência cronológica, baseada na linearidade dos fatos, apenas evidenciando a descrição dos acontecimentos havidos, apartada da realidade imediata. A História da Educação é parte integrante da história total, deve abandonar uma perspectiva institucional estreita de maneira a integrar o conjunto das dimensões econômica, social e política, deve refutar a narração gloriosa de um progresso continuamente assegurado pela escola. Mas, para essa disciplina conseguir acrescentar algo para os estudantes, é preciso que se distancie do paradigma dominante (Santos, 2002) como discurso que institui um modelo de racionalidade da Modernidade e procure aproximar-se dos saberes e dos anseios dos alunos. Portanto, precisa estar atrelada às vivências e realidades educacionais do país na contemporaneidade. Assim, o mais importante é pensar em uma história da educação que atenda às demandas do presente, que responda a indagações que partam do contexto em que se vive a fim de procurar satisfazer as necessidades de uma historiografia engajada na luta por uma educação de fato inclusiva, sem abandonar o compromisso social que dela se espera.

É preciso ousar e construir alguns desvios à perspectiva eminentemente eurocêntrica, valorizando culturas que tenham afinidades com as realidades de nosso país: as culturas dos povos indígenas brasileiros, as culturas africanas, ainda desconhecidas em grande parte, e as culturas da América Latina, igualmente silenciadas ao longo do tempo. Contudo, não sejamos ingênuos a ponto de negar totalmente as referências históricas europeias. A História do Brasil está atrelada ao Velho Continente, a compreensão de uma série de fenômenos europeus leva a um maior entendimento do que acontecia no Brasil. Por exemplo, como entender a primeira experiência de 
ensino público no Brasil, as aulas régias, sem relacioná-las à expulsão dos jesuítas a partir de 1759, tendo em vista que a Companhia de Jesus dominava a escolarização na colônia portuguesa até então?

Ao invés de um tempo de certezas absolutas, a História Cultural postula a restauração da dúvida (Pesavento, 2004) como princípio do conhecimento e a pluralidade de respostas para o âmbito de resultados obtidos. Isso não quer dizer que se caia no relativismo absoluto, mas que se admita que as coisas não precisam ser isto ou aquilo. Nas palavras de Pesavento (2000): "o fim das certezas pode ser incômodo e até mesmo abalar a segurança do próprio conhecimento de cada um, mas eu prefiro a dúvida à certeza, pois é a primeira que estimula o ato de conhecer e impele à investigação e à descoberta" (p. 15).

\section{Desnaturalizar e desestabilizar}

Comumente, as aulas de História da Educação, e de tantas outras disciplinas, têm seu início marcado pela apresentação de um plano de ensino. Uma professora ou um professor entrega o cronograma dos encontros, comenta a sua metodologia, os procedimentos de avaliação, faz referências à bibliografia. As unidades temáticas propostas, ressalvadas as exceções, obedecem a uma sequência cronológica e elencam aspectos considerados relevantes da educação em cada época da História. No entanto, penso que, antes de tudo, se faz necessário uma reflexão acerca das questões que marcam a educação na realidade presente. É preciso buscar os detalhes, as idiossincrasias, aquilo que pode parecer prosaico, banal. Neste sentido, assumem relevância aspectos singelos que, em uma concepção tradicional, podem parecer folclóricos ou sem significado, mas, na perspectiva desta abordagem, adquirem uma ampla repercussão nas aulas, investindo o presente de um sentido afetivo em relação ao passado.

Eliane Lopes e Ana Galvão (2010) alertam para as possíveis dificuldades de quem vive a escola cotidianamente em poder refletir e estranhar aquilo que caracteriza o ambiente escolar e seus atores sociais. Nas palavras das autoras, "muito do que ocorre no universo da educação ainda é pouco conhecido pelos pesquisadores - e mesmo pelos professores. [...] nem sempre eles conseguem perceber [...] qual é o sentido de cada uma das cenas que compõem o dia a dia da escola" (p. 11).

Então, parece-me importante estranhar e indagar inúmeras situações cotidianas. Por que os alunos ficam por mais de quatro horas sentados em classes escolares, dispostas em filas? Por que os currículos contemplam uma grande carga horária para as chamadas ciências exatas e aulas de História e Geografia situam-se em um plano secundário? Por que os pátios de muitas escolas foram construídos de modo a favorecer a visão de tudo o que acontece ao redor? O que nos dizem cadernos, diários de professoras, fotografias, cartilhas, mobiliário e uniformes escolares? Por que muitas culturas juvenis ainda são ignoradas pela escola? Como a escola se constituiu em um espaço ocupado maciçamente por professoras? O que levou à desvalorização social da profissão de professor? Essas e tantas outras questões precisam ser desnaturalizadas, e um dos espaços propícios, no meio acadêmico, são as aulas de História da Educação. Longe da ideia de pensar que a História da Educação possa oferecer uma resposta que satisfaça plenamente as referidas indagações, podemos, isto sim, buscar no passado insights que sempre carregarão as marcas da provisoriedade e que produzirão, inevitavelmente, novas provocações. Neste sentido, pensar nos desafios da educação na contemporaneidade exige que se conheçam os percursos trilhados pela educação no passado.

O estudo da História da Educação nos remete a tempos e espaços diversos, faz com que nos defrontemos com esse "outro" (Lopes e Galvão, 2010, p. 11). Essa disposição para a alteridade promove a aproximação daquilo que é distinto de nós e que, portanto, não conhecemos. Segundo as autoras: 
Para fazer história, é necessário estar radicalmente disposto a ler, ver, ouvir e contar o outro. Imersos num presente que traz indagações, impõe questões e sugere temáticas, os pesquisadores e os professores atentos formulam problemáticas para a história: o que se fazia, por que se fazia, quem fazia, como se fazia algo em determinada época, numa sociedade específica? (2010, p. 12).

Neste sentido, localizar-se no tempo e no espaço é condição sine qua non para o estudante conseguir estabelecer relações entre os fatos tidos como notáveis de cada época. É aqui que entram em cena as noções básicas de duração, sucessão e simultaneidade temporal. Para situar-se no tempo, é preciso ter claras essas três noções. $\mathrm{Na}$ escola, via de regra, aprende-se muito mais a sucessão, materializada nas linhas de tempo que povoam nossas lembranças das aulas de História, um fato após o outro, elencados em uma linha horizontal, memorizavam-se as datas e seu significado e, pronto, aprendiase o conteúdo. Sabemos que essa forma fragmentada de aprender História é de pouca valia. Para uma maior compreensão, se faz necessário entender a simultaneidade do tempo, ou seja, paralelamente, diversas histórias acontecem em diferentes lugares, a maioria delas desconhecidas. É uma noção especialmente complexa para as crianças, pois exige certo descentramento e implica no desenvolvimento do conceito de alteridade. Resta falar do conceito de duração do tempo, algo que parece tão simples, mas está carregado de significado que envolve entender a quantificação do tempo na História.

A título de exemplificar, enquanto ocorria o Movimento da Contra Reforma Católica na Europa, o que acontecia nas terras além-mar? No tempo em que Rousseau escrevia o Emílio, o que marcava a educação na História do Brasil? Que relações podemos estabelecer entre a utopia de Comenius e a educação no Brasil do século XXI? Quanto tempo duraram as práticas punitivas, especialmente o uso da palmatória? Quais são as práticas punitivas aplicadas hoje em dia? Depois que o Brasil mudou sua forma de governo e tornou-se uma República, o que aconteceu com a educação no país?

Segundo Bergamaschi (2002, p. 24), é preciso ir além do conhecimento da sequência cronológica dos fatos da História; é necessário que os alunos se apropriem dessas noções temporais básicas e, assim, consigam se localizar e se organizar no tempo histórico, diferenciem e relacionem temporalidades, percebam a existência de diferentes ritmos e épocas, bem como o entrelaçamento entre histórias individuais e coletivas.

\section{Aulas de História da Educação?}

A grande questão que persegue este texto é pensar a disciplina História da Educação e suas articulações no processo formativo das alunas do Curso de Pedagogia ${ }^{3}$ da Faculdade de Educação da Universidade Federal do Rio Grande do Sul (FACED/UFRGS). Como seduzir as alunas para a discussão acerca dos temas que envolvem a História da Educação? Creio que este é o maior desafio dos professores de História da Educação: atribuir sentidos efetivos e afetivos à sua disciplina e não apenas abordar, em suas aulas, saberes que não promovam interlocuções, que não surtam efeitos no modo como se entende a educação atualmente.

\footnotetext{
3 O Curso de Pedagogia da Faculdade de Educação/UFRGS passou por uma reformulação em 2007, atendendo às orientações das Diretrizes Curriculares Nacionais para os Cursos de Pedagogia (Resolução CNE/CP No 1, 15/05/2006) e procurando desenvolver a formação de profissionais simultaneamente docentes, pesquisadores e dirigentes de processos educacionais em espaços de educação formais e não formais. O Curso busca formar profissionais habilitados para o exercício da docência na Educação Infantil e Anos Iniciais do Ensino Fundamental, nos Cursos de Ensino Médio, na modalidade Normal e Cursos de Educação Profissional na área de serviços, apoio a escolas e outras áreas em que sejam previstos conhecimentos pedagógicos. (www.ufrgs.br/faced/comissões/comgrad).
} 
Cabe ressaltar que o Curso de Pedagogia da Faculdade de Educação/UFRGS compreende duas disciplinas, cada uma com quatro créditos, de História da Educação: a primeira oferecida no primeiro semestre do curso e intitulada História da Educação na Europa e nas Américas, e a outra, História da Educação do Brasil, que integra as disciplinas do quinto semestre. É intencional essa distância temporal entre o primeiro e o quinto semestres do curso, justamente para não parecer que os estudos da Pedagogia iniciam com discussões teóricas e depois prevalecem apenas disciplinas de caráter eminentemente pedagógico. A intenção é que as alunas percebam as inter-relações entre teoria e empiria e como essas interfaces comparecem em todas as etapas do curso. Assim, através de sua proposta curricular, a Faculdade de Educação sinaliza suas concepções acerca do que deve ser a formação e atuação profissional dos docentes.

Voltando a pensar nas aulas de História da Educação, vê-se que, em outras épocas, eram comuns narrativas discentes que relatavam o encantamento com a performance dos professores, elogiados por ficarem horas a falar, via de regra sozinhos, sobre a educação em distintos tempos e espaços - no Egito Antigo, na Índia do passado, na época medieval, por exemplo. Eram aulas em que o aluno limitava-se a escutar o professor, acompanhava as aulas pela leitura dos manuais, sem investigar e problematizar os temas apresentados. Ainda há programas dessa disciplina em faculdades que contemplam, em um único semestre, a história da educação desde os tempos da chamada pré-história até os dias atuais, como se fosse um rápido passeio cronológico. Questiona-se: qual o valor desse saber enciclopédico diante da realidade educacional brasileira?

Mas, pragmaticamente falando, qual é a utilidade da História da Educação? Penso que o fato de vivermos em uma sociedade altamente individualista e competitiva nos conduz ao emprego desta palavra, utilidade. A busca por um saber imediato, utilitário no sentido mais raso do termo, sem dúvida, apresenta-se como um dificultador para se avaliar o significado dessa disciplina nos cursos de formação docente. Conhecer o passado nos ajuda a avaliar as atitudes de homens e de mulheres de outros tempos? Ainda vale a célebre frase aprender com os erros do passado para não repeti-los? Seria esse o papel da História? É possível, de acordo com Lopes e Galvão (2010), pensar que a História, juntamente com outras formas de explicação da realidade, nos ajude para que possamos compreender alguns aspectos que o presente nos apresenta como problemas. Nas palavras das autoras: "Talvez muitos alunos e professores tenham dificuldades para responder 'para que serve a História?’ e, particularmente, a História da Educação. Afinal, o trabalho cotidiano em sala de aula exige respostas rápidas, seguras, diretas" (p. 12).

Algo importante, nas aulas de História da Educação, é instigar os alunos a refletir que todos nós somos sujeitos da História da Educação, não sujeitos no sentido essencialista, autônomo, mas seres que fazem parte da História da Educação, influenciados pelos discursos circulantes na sociedade, dotados de múltiplas identidades. Michel Foucault explica que mulheres e homens "tornam-se sujeitos", "aprendem a reconhecer-se como sujeitos" (Foucault, 1995 p. 232), assujeitam-se aos discursos que circulam no tecido social. Segundo Rago (2003, p. 77), “os indivíduos se produzem e são produzidos numa determinada cultura, através de determinadas práticas e discursos, enquanto subjetividades". Portanto, Foucault distancia-se de uma visão fundante e essencialista de um sujeito eminentemente individual. Analisa o sujeito como alguém que é produzido histórica e culturalmente pelas práticas sociais (Foucault, 2001b, p. 16).

Nesse sentido, uma atividade muito significativa é a proposta da escrita de um memorial, ou seja, uma escrita autobiográfica em que cada aluno faz um balanço do vivido, tendo a possibilidade de ressignificar suas histórias de vida, especialmente refletir acerca de sua trajetória de escolarização. Assim, valorizam-se subjetividades de cada aluno, pois podem expressar seus jeitos de ser, viver, através do reconhecimento de suas memórias pessoais e coletivas, que revelam um universo de valores morais, éticos, crenças, atitudes, normas e regras de convívio do seu contexto social. Ao rememorar suas histórias de vida, articulam-se experiências individuais e 
coletivas. Ao falar, o sujeito se aproxima de seus grupos de referência, revela sua percepção de como vê a si mesmo e de como os outros o veem. Como diz Nóvoa (2004), "a inscrição de nosso percurso pessoal e profissional permite uma compreensão crítica de 'quem fomos' e de 'como somos' (p. 11).

Alistair Thomson salienta que as evocações das nossas memórias podem "proporcionar uma afirmação positiva de identidade para o narrador, para os membros de uma comunidade particular e para o mundo lá fora" (2002, p. 351). Em suas narrativas, os sujeitos selecionam determinadas lembranças e, nessas recordações, traduzem, também, as histórias de sua coletividade, que se imbricam com as histórias individuais. Para Thomson (Ibid.), todos os elementos das narrativas são reveladores das experiências vividas pela coletividade, e isso vale tanto para o que é enfatizado quanto para o que é silenciado. Maria Helena Bastos reforça a ideia ao afirmar que, "ao escrever sobre si, o professor apropria-se de sua história e de uma parte importante de sua vida" (2003, p. 170).

Continuando, é importante apresentar propostas de aulas de História da Educação que discutam temáticas que envolvam o aluno em suas ancestralidades e isso passa pela inclusão de histórias que, durante muito tempo, foram silenciadas e apagadas. Assim, uma História da Educação do Brasil que priorize o estudo da história da educação dos povos indígenas, das populações afrodescendentes, das mulheres, das crianças, das culturas juvenis, de outras etnias consideradas minoritárias, pode fazer a diferença no comprometimento e no engajamento do aluno. Sem abrir mão de um conhecimento mais factual, no sentido dos grandes marcos da escolarização brasileira, tal proposta permite que o aluno perceba a força viva da História da Educação, presente nos rastros deixados pelo passado, e possibilita o desenvolvimento de princípios e valores como solidariedade, cooperação, participação, tolerância e aceitação das diferenças, suas aulas sensibilizam os alunos para uma aproximação, para o diálogo e para o "acolhimento ao outro" (Hickmann, 2002, p. 11).

Outros aliados na composição das aulas de História da Educação são a literatura e o cinema. Chaves, Seffner e Bica Jr. (2002) explicam que é histórica a literatura que, mesmo fictícia, assuma como preocupação central a expressão de visão histórica de uma determinada época. $\mathrm{O}$ mesmo vale em relação a filmes, pois, nos dois casos (literatura e cinema), apresentam-se explicações acerca de uma realidade, versões de uma história, eles constituem-se em observatórios, representações de uma época que falam sobre fatos não mais possíveis de reconstruir pela experiência vivida. Importa dizer que o conhecimento histórico comporta a ficção sim, uma espécie de "ficção controlada", nas palavras de Pesavento (2004), pois se sustenta a partir de documentos. Então, falando em literatura, que belas representações de escola, de aluno e de professor têm-se a partir da leitura do "Conto de Escola", de Machado de Assis, ou do "Ateneu", de Raul Pompeia. Machado de Assis avalia o legado que a escola lhe deixou: "delação e corrupção". Tanto no "Conto de Escola" como no "Ateneu”, a escola é percebida como lugar sombrio, em que não se é livre, se está sob constante vigilância, exercida por professores autoritários que aterrorizam os alunos.

Pensando na construção da profissão de professora, uma leitura interessante é o romance "Clarissa", de Érico Verissimo, em que o autor conta a história de uma jovem normalista interiorana que vem estudar na Escola Normal em Porto Alegre. Uma narrativa semelhante é "Minha vida de menina" (1999), que apresenta a autobiografia de Helena Morley, em que narra suas vivências juvenis no interior de Minas Gerais e sua formação na Escola Normal da cidade. Não poderia deixar de referir a obra "Uma Professora Maluquinha", em que Ziraldo rememora sua infância e nos apresenta uma professora especial que marcou seus primeiros anos de escolarização. Uma professora transgressora para os padrões vigentes de educação, talvez imbuída dos princípios da Escola Nova que se manifestavam em sua forma de ensinar, em sua relação com os alunos, no enfrentamento aos conflitos com aquela sociedade típica dos anos 1940 no Brasil. E ainda é preciso destacar o livro "Alfabetto: autobiografia escolar", de Frei Betto (2003), em que o autor escreve de forma singular 
sua trajetória escolar, iniciando pelo "jardim de infância”, até chegar aos anos da ditadura civilmilitar no Brasil e as profundas implicações desse período em sua vida.

Quanto aos filmes, como falar da educação na época medieval sem assistir "O Nome da Rosa", inspirado no clássico de Umberto Eco com o mesmo título? Sua trama instigante põe em xeque as certezas medievais, discute os conceitos de ciência e de homem em moldes iluministas, fala de razão, de sensibilidade e de críticas ao clero católico. Igualmente apaixonante, "Em nome de Deus" mostra a emergência da profissão de professor no Ocidente Medieval, a partir da história do Professor da Universidade de Paris, Pedro Abelardo, e seu amor por Heloísa. Dividido entre o amor por Heloísa e a profissão de professor, associada aos votos de castidade e sacerdócio, Abelardo protagoniza as angústias do ofício, de certa forma, ainda vividas pelos docentes no século XXI.

Por falar em profissão de professor e no papel da escola na sociedade, são interessantes as abordagens sobre educação de muitos filmes, de décadas passadas, que se passam em escolas nas periferias de cidades norte-americanas, seus alunos são indisciplinados e, via de regra, latinos, orientais ou negros, ao estilo "Meu mestre, minha vida", "Ao mestre com carinho" e, mais recentemente, "Escritores da liberdade". Em comum, essas tramas contam a história de professores e suas dificuldades com os alunos, apresentam o discurso da escola redentora e do professor capaz de enfrentar sozinho as maiores adversidades e, por conta própria, conduzir os alunos para outros caminhos, longe da marginalidade, longe dos crimes e das drogas, a fim de inseri-los naquela sociedade.

Outra forma de envolver os alunos é instigá-los a perceber a História da Educação além do seu caráter disciplinar, concebendo-a, também, como campo de pesquisas. Em uma época que tanto se fala de cultura, são válidas e significativas as visitas a museus escolares, momentos em que é possível propor que os alunos desenvolvam exercícios de investigação, produzindo uma espécie de inventário de fontes de determinadas escolas que promovem uma aproximação mais concreta do cotidiano escolar de outros tempos, através da observação e análise da arquitetura do prédio escolar, de escritos, fotos, cadernos, diários, livros didáticos, artefatos escolares, um passeio pelos seus arquivos, consulta a boletins, atas, cadernos, jornais escolares, observação de fotografias, narrativas de memória de antigos professores e ex-alunos, entre tantas outras possibilidades. Atualmente, muitas instituições escolares começam a valorizar suas memórias e organizar espaços em que reúnem fragmentos da documentação que sobreviveu ao tempo, disponibilizando o acervo à visitação do público em geral. Para estudantes e professores de História da Educação, esses lugares são especiais, pelas muitas possibilidades de estudo e problematização daquilo que foi preservado do passado escolar. O que a escola guardou? O que não guardou? Por que guardou? Como descartou? O que foi descartado? Que história está sendo contada no museu escolar? Ao observar as fotos de alunos e professores, por exemplo, como estão se portando, que roupas vestem, há presença de negros e indígenas?

Entretanto, importa lembrar que as fontes históricas não correspondem diretamente ao passado tal qual aconteceu. Precisam de leitura, de análise, de questionamentos para que possam, aos poucos, fornecer indícios, cruzamentos necessários para a reconstrução do passado. É preciso que se indague qualitativamente as fontes de pesquisa para, depois, estabelecer intervenções competentes junto aos seus alunos na busca de uma compreensão mais fecunda desse mesmo passado. Todo esse conjunto de documentos diz muito, e, se problematizado, é capaz de explicar um pouco da história de uma instituição de ensino. E, desse modo, se consegue perceber o quanto a História da Educação está viva nas escolas, materializada nesses fragmentos conservados pelo tempo e pelas narrativas de memória.

Nóvoa (2004) nos ajuda a pensar no ensino de História da Educação, que pode incluir atividades de estudo e de investigação. Nóvoa (2004) debruçou-se sobre este tema e reforça os desafios vividos pelos docentes dessa disciplina que agregam em seu ofício, concomitantemente, o 
papel de historiador e de professor, o que faz com que transitem pela História e pela Educação. Cabe aqui o alerta de Clarice Nunes (2003) sobre o papel desses professores que, por diferentes motivos, nem sempre são pesquisadores identificados com a História da Educação e isso dificulta sua inserção diante do campo de pesquisa e também pode comprometer a qualidade daquilo que trabalha em suas aulas. Nunes ressalta que a percepção da História da Educação como campo de pesquisa e disciplina é algo que pode "inundar o dia a dia da sala de aula" (p. 152). Nesse sentido, é importante envolver os alunos a trabalhar as questões historiográficas, percebendo, na prática, a História da Educação enquanto possibilidade de desenvolver pesquisas, indicando caminhos de aprimoramento acadêmico através da participação em bolsas de iniciação científica, de trabalhos de conclusão de curso e em cursos de pós-graduação de Mestrado e Doutorado identificados à História da Educação.

\section{Ainda por dizer}

Neste texto, procurou-se discutir os significados da História da Educação especialmente pensando na formação das alunas do Curso de Pedagogia. Como professora desta disciplina, sintome profundamente implicada em tudo o que escrevi. É assim que busco a cada novo semestre, a cada turma, a cada nova aula, aguçar minha sensibilidade, valorizar minhas intuições no sentido de construir propostas de aulas que, de alguma forma, venham ao encontro dos desejos das pessoas que me escutam nas salas de aula da Faculdade de Educação/UFRGS. Procuro ficar atenta aos olhares das alunas, procurando perceber o quanto as propostas que apresento provocam ou não eco em suas falas, despertam ressonâncias nas conversas que se seguem. Mais do que nunca, é preciso que os saberes difundidos nos cursos de graduação agreguem sentidos para os alunos. Mais do que nunca, a sala de aula precisa ser compreendida enquanto um espaço de construção de conhecimento, de trocas e de afetos.

Ao longo desses escritos, afirmou-se que aulas de História da Educação são importantes no processo de consituição de futuros professores que, imbuídos desses saberes, poderão perceber que o conhecimento da História dá sentido ao trabalho educativo, pois o presente está atrelado ao passado.

Encerro essas reflexões com mais uma ideia de Nóvoa que, de certa forma, sintetiza as competências desse sujeito, professor de História da Educação. Ele afirma que: "o mínimo que se exige de um historiador é que seja capaz de pensar a História interrogando os problemas do presente [...]. O mínimo que se exige de um educador é que seja capaz de pensar a sua ação nas continuidades e mudanças do tempo" (2004, p. 9). Assim, essa espécie de aliança entre História e Educação poderá instigar as alunas a desenvolverem uma participação crítica na realidade escolar em que, depois de formadas, irão se inserir.

\section{Referências}

Bastos, M.H. Memoriais de professoras: reflexões sobre uma proposta. In. Mignot, A.C.V. e Cunha, M.T.S. (orgs.) (2003). Práticas de memória docente. São Paulo: Cortez.

Bergamaschi, M. B. O tempo histórico no ensino fundamental. In. Hickmann, R. I. (2002) Estudos Sociais: outros saberes e outros sabores. Porto Alegre: Mediação.

Frei Betto. (2003) Alfabetto: autobiografia escolar. São Paulo: Ática.

Bittencourt, C.M.F. (2008) Ensino de História: fundamentos e métodos. São Paulo: Cortez.

Bourdieu, P.; Chamboredon, J. C.; Passeron, J.C. (1999) A profissão de sociólogo: preliminares epistemológicas. Petrópolis: Vozes. 
Brecht, B. Perguntas de um trabalhador que lê. Disponível em: http://recantodasletras.uol.com.br. Acesso em: 28 abr. 2012.

Burke, P. (1996) A escrita da História: novas perspectivas. São Paulo: Editora da Universidade Estadual Paulista.

Certeau, M. (1996) A invenção do cotidiano. Petrópolis: Vozes.

Chartier, R. Uma crise da história? A história entre narração e conhecimento. In: Pesavento, S. J. (2001) Fronteiras do Milênio. Porto Alegre: Editora da UFRGS.

Chartier, R. (2002) À beira da falésia: a história entre certezas e inquietude. Porto Alegre: Editora da Universidade/UFRGS.

Chaves, F. L.; Seffner, F.; Bicca Jr, R. Um projeto de trabalho a partir da relação história e literatura. In. Hickmann, R. I. (2002) Estudos Sociais: outros saberes e outros sabores. Porto Alegre: Mediação.

Fonseca, T.N.L. História da Educação e História Cultural. In. Veiga, C.G. e Fonseca, T.N.L. (2008) História e Historiografia da Educação no Brasil. Belo Horizonte: Autêntica.

Foucault, M. (1995) A arqueologia do saber. Rio de Janeiro: Forense Universitária.

Foucault, M. (1992) As palavras e as coisas: uma arqueologia das ciências humanas. São Paulo: Martins Fontes.

Foucault, M. (2001a) La vida de los hombres infames. Buenos Aires: Editorial Altamira.

Foucault, M. (2001b) A Ordem do Discurso. São Paulo: Loyola.

Gullar, F. (1999) In. Neves, M.T. et allii. Fontes históricas: possibilidades de construção do conhecimento histórico no ensino fundamental. Projeto: Revista de Educação, ano 2, n. 2, p. 43, jan./jun.

Hickmann, R. I. (2002) Estudos Sociais: outros saberes e outros sabores. Porto Alegre: Mediação.

Lopes, E. M. T. e Galvão, A. M. O. (2010) Território plural: a pesquisa em História da Educação. São Paulo: Ática.

Morley, H. (1999) Minha vida de menina. São Paulo: Cia das Letras.

Nóvoa, A. Apresentação. In. Stephanou, M. e Bastos, M. H. C. (orgs.). (2004) Histórias e Memórias da Educação no Brasil. Petrópolis: Vozes.

Nunes, Z.C.R.M. (2003) O ensino de História da Educação e a produção de sentidos na sala de aula. RBHE. Campinas: São Paulo, n. 06, p. 115-158.

Pesavento, S. J. (2004) História e História Cultural. Belo Horizonte: Autêntica.

Pesavento, S. J. (2000) Que história é essa? Uma incursão nos desafios do presente. Projeto Revista de Educação: História. Porto Alegre: Projeto, v. 2, n. 2.

Rago, M. Libertar a História. In: Rago, M.; Orlandi, L. B. O.; Veiga-Neto, A. (orgs.). (2003) Imagens de Foucault e Deuleų̧: ressonâncias nietzchianas. Rio de Janeiro: DP\&A.

Ranciére, J. Sobre a história das mulheres no século XIX. In: Duby, G. e Perrot, M. (1995) As mulheres e a História. Lisboa: Rolo \& Filhos Artes Gráficas.

Ribeiro, R. J. (1999) Não há pior inimigo do conhecimento que a terra firme. Tempo SocialRevista Tempo Social (USP), v. 11, n. 01, p. 189-195, maio.

Santos, B. S. (2002) Um discurso sobre as ciências. Porto: Edições Afrontamento.

Santos, B.S. (1993) Modernidade, identidade e cultura de fronteira. Tempo social - Revista de Sociologia, USP/ São Paulo 5 (1-2): 31-52 (editado em nov. 1994).

Sarmento, M. J. O estudo de caso etnográfico em educação. In: Zago, N., Carvalho, M. P. de e Vilela, R. A. T. (orgs.). (2003) Itinerários de pesquisa: perspectivas qualitativas em Sociologia da Educação. Rio de Janeiro: DP\&A.

Thomson, A. (1997) Recompondo a memória: questões sobre a relação entre a História Oral e as memórias. Projeto História: São Paulo, (15), abril, p. 51 a 84. 
Thomson, A. (2002) Histórias (co)movedoras: História Oral e estudos de migração. Revista Brasileira de História. São Paulo. V. 22, n. 44, p. 341-364.

Thomson, A. (2001) Memórias de Anzac: colocando em prática a teoria da memória popular na Austrália. Revista da Associação Brasileira de História Oral. N.4, junho, p. 85-101. 


\section{Sobre a Autora}

\section{Dóris Bittencourt Almeida}

Universidade Federal do Rio Grande do Sul

Doutora em Educação pela Universidade Federal do Rio Grande do Sul. Professora Adjunta no Departamento de Educação Básica da Faculdade de Educação.

almeida.doris@gmail.com

\section{Sobre as Editoras Convidadas}

\section{Carla Beatriz Meinerz}

Universidade Federal do Rio Grande do Sul

Doutora em Educação pela Universidade Federal do Rio Grande do Sul. Professora Adjunta no Departamento de Ensino e Currículo da Faculdade de Educação.

carlameinerz@gmail.com

\section{Dóris Maria Luzzardi Fiss}

Universidade Federal do Rio Grande do Sul

Doutora em Educação pela Universidade Federal do Rio Grande do Sul. Professora Adjunta no

Departamento de Ensino e Currículo da Faculdade de Educação.

fiss.doris@gmail.com

\section{Sônia Mara Moreira Ogiba}

Universidade Federal do Rio Grande do Sul

Mestre em Educação pela Universidade Federal do Rio Grande do Sul. Professora no

Departamento de Ensino e Currículo da Faculdade de Educação. Membro da Associação

Psicanalítica de Porto Alegre (APPOA) e Instituto APPOA - Clínica, Pesquisa e Intervenção

Social.

ogb@cpovo.net

\section{DOSSIÊ \\ FORMAÇÃO DE PROFESSORES E PRÁTICAS CULTURAIS \\ arquivos analíticos de políticas educativas}
Volume 21 Número 23
25 de março, 2013
ISSN 1068-2341

\section{(c)}

SORERIGHIS RESEREED O Copyright e retido pelo/a o autor/a (ou primeiro co-autor) que outorga o direito da primeira publicação à revista Arquivos Analíticos de Políticas Educativas. Más informação da licença de Creative Commons encontram-se em http://creativecommons.org/licenses/by-nc-nd/2.5. Qualquer outro uso deve ser aprovado em 
conjunto pelo/s autor/es e por AAPE/EPAA. AAPE/EPAA é publicada por Mary Lou Fulton Institute Teachers College da Arizona State University. Os textos publicados em AAPE são indexados por CIRC (Clasificación Integrada de Revistas Científicas, Espanha) DIALNET (Espanha),Directory of Open Access Journals, Education Full Text (H.W. Wilson), EBSCO Education Research Complete, , ERIC, , QUALIS A2 (Brasil), SCImago Journal Rank; SCOPUS, SOCOLAR (China). Contribua com comentários e sugestões a http://epaa.info/wordpress/ ou para Gustavo E. Fischman fischman@asu.edu.

Curta a nossa comunidade EPAA's Facebook https://www.facebook.com/EPAAAAPE e Twitterfeed@epaa_aape. 


\section{arquivos analíticos de políticas educativas conselho editorial}

Editor: Gustavo E. Fischman (Arizona State University) Editores Associados: Rosa Maria Bueno Fisher e Luis A. Gandin

(Universidade Federal do Rio Grande do Sul)

Dalila Andrade de Oliveira Universidade Federal de Minas Gerais, Brasil

Paulo Carrano Universidade Federal Fluminense, Brasil

Alicia Maria Catalano de Bonamino Pontificia Universidade Católica-Rio, Brasil

Fabiana de Amorim Marcello Universidade Luterana do Brasil, Canoas, Brasil

Alexandre Fernandez Vaz Universidade Federal de Santa Catarina, Brasil

Gaudêncio Frigotto Universidade do Estado do Rio de Janeiro, Brasil

Alfredo M Gomes Universidade Federal de Pernambuco, Brasil

Petronilha Beatriz Gonçalves e Silva Universidade Federal de São Carlos, Brasil

Nadja Herman Pontificia Universidade Católica -Rio Grande do Sul, Brasil

José Machado Pais Instituto de Ciências Sociais da Universidade de Lisboa, Portugal

Wenceslao Machado de Oliveira Jr. Universidade Estadual de Campinas, Brasil
Jefferson Mainardes Universidade Estadual de Ponta Grossa, Brasil

Luciano Mendes de Faria Filho Universidade Federal de Minas Gerais, Brasil

Lia Raquel Moreira Oliveira Universidade do Minho, Portugal

Belmira Oliveira Bueno Universidade de São Paulo, Brasil

António Teodoro Universidade Lusófona, Portugal

Pia L. Wong California State University Sacramento, U.S.A

Sandra Regina Sales Universidade Federal Rural do Rio de Janeiro, Brasil

Elba Siqueira Sá Barreto_Fundação Carlos Chagas, Brasil

Manuela Terrasêca Universidade do Porto, Portugal

Robert Verhine Universidade Federal da Bahia, Brasil

Antônio A. S. Zuin Universidade Federal de São Carlos, Brasil 


\section{education policy analysis archives editorial board}

Editor Gustavo E. Fischman (Arizona State University)

Associate Editors: David R. Garcia (Arizona State University), Stephen Lawton (Arizona State University)

Rick Mintrop, (University of California, Berkeley) Jeanne M. Powers (Arizona State University)

Jessica Allen University of Colorado, Boulder

Gary Anderson New York University

Michael W. Apple University of Wisconsin, Madison

Angela Arzubiaga Arizona State University

David C. Berliner Arizona State University

Robert Bickel Marshall University

Henry Braun Boston College

Eric Camburn University of Wisconsin, Madison

Wendy C. Chi* University of Colorado, Boulder

Casey Cobb University of Connecticut

Arnold Danzig Arizona State University

Antonia Darder University of Illinois, UrbanaChampaign

Linda Darling-Hammond Stanford University

Chad d'Entremont Strategies for Children

John Diamond Harvard University

Tara Donahue Learning Point Associates

Sherman Dorn University of South Florida

Christopher Joseph Frey Bowling Green State University

Melissa Lynn Freeman* Adams State College

Amy Garrett Dikkers University of Minnesota

Gene V Glass Arizona State University

Ronald Glass University of California, Santa Cruz

Harvey Goldstein Bristol University

Jacob P. K. Gross Indiana University

Eric M. Haas WestEd

Kimberly Joy Howard* University of Southern California

Aimee Howley Ohio University

Craig Howley Ohio University

Steve Klees University of Maryland

Jaekyung Lee SUNY Buffalo
Christopher Lubienski University of Illinois, UrbanaChampaign

Sarah Lubienski University of Illinois, UrbanaChampaign

Samuel R. Lucas University of California, Berkeley

Maria Martinez-Coslo University of Texas, Arlington

William Mathis University of Colorado, Boulder

Tristan McCowan Institute of Education, London

Heinrich Mintrop University of California, Berkeley

Michele S. Moses University of Colorado, Boulder

Julianne Moss University of Melbourne

Sharon Nichols University of Texas, San Antonio

Noga O'Connor University of Iowa

João Paraskveva University of Massachusetts, Dartmouth

Laurence Parker University of Illinois, UrbanaChampaign

Susan L. Robertson Bristol University

John Rogers University of California, Los Angeles

A. G. Rud Purdue University

Felicia C. Sanders The Pennsylvania State University Janelle Scott University of California, Berkeley

Kimberly Scott Arizona State University

Dorothy Shipps Baruch College/CUNY

Maria Teresa Tatto Michigan State University

Larisa Warhol University of Connecticut

Cally Waite Social Science Research Council

John Weathers University of Colorado, Colorado Springs

Kevin Welner University of Colorado, Boulder

Ed Wiley University of Colorado, Boulder

Terrence G. Wiley Arizona State University

John Willinsky Stanford University

Kyo Yamashiro University of California, Los Angeles

* Members of the New Scholars Board 


\section{archivos analíticos de políticas educativas consejo editorial}

Editor: Gustavo E. Fischman (Arizona State University) Editores. Asociados Alejandro Canales (UNAM) y Jesús Romero Morante (Universidad de Cantabria)

Armando Alcántara Santuario Instituto de Investigaciones sobre la Universidad y la Educación, UNAM México

Claudio Almonacid Universidad Metropolitana de Ciencias de la Educación, Chile

Pilar Arnaiz Sánchez Universidad de Murcia, España

Xavier Besalú Costa Universitat de Girona, España Jose Joaquin Brunner Universidad Diego Portales, Chile

Damián Canales Sánchez Instituto Nacional para la Evaluación de la Educación, México

María Caridad García Universidad Católica del Norte, Chile

Raimundo Cuesta Fernández IES Fray Luis de León, España

Marco Antonio Delgado Fuentes Universidad Iberoamericana, México

Inés Dussel FLACSO, Argentina

Rafael Feito Alonso Universidad Complutense de Madrid, España

Pedro Flores Crespo Universidad Iberoamericana, México

Verónica García Martínez Universidad Juárez Autónoma de Tabasco, México

Francisco F. García Pérez Universidad de Sevilla, España

Edna Luna Serrano Universidad Autónoma de Baja California, México

Alma Maldonado Departamento de Investigaciones Educativas, Centro de Investigación y de Estudios Avanzados, México

Alejandro Márquez Jiménez Instituto de Investigaciones sobre la Universidad y la Educación, UNAM México

José Felipe Martínez Fernández University of California Los Angeles, USA
Fanni Muñoz Pontificia Universidad Católica de Perú

Imanol Ordorika Instituto de Investigaciones Economicas - UNAM, México

Maria Cristina Parra Sandoval Universidad de Zulia, Venezuela

Miguel A. Pereyra Universidad de Granada, España

Monica Pini Universidad Nacional de San Martín, Argentina

Paula Razquin UNESCO, Francia

Ignacio Rivas Flores Universidad de Málaga, España

Daniel Schugurensky Universidad de Toronto-Ontario Institute of Studies in Education, Canadá

Orlando Pulido Chaves Universidad Pedagógica Nacional, Colombia

José Gregorio Rodríguez Universidad Nacional de Colombia

Miriam Rodríguez Vargas Universidad Autónoma de Tamaulipas, México

Mario Rueda Beltrán Instituto de Investigaciones sobre la Universidad y la Educación, UNAM México

José Luis San Fabián Maroto Universidad de Oviedo, España

Yengny Marisol Silva Laya Universidad Iberoamericana, México

Aida Terrón Bañuelos Universidad de Oviedo, España

Jurjo Torres Santomé Universidad de la Coruña, España

Antoni Verger Planells University of Amsterdam, Holanda

Mario Yapu Universidad Para la Investigación Estratégica, Bolivia 